\title{
Effects of methylphenidate on working memory in pigeons
}

\author{
FIONA K. WRIGHT and K. GEOFFREY WHITE \\ University of Otago, Dunedin, New Zealand
}

\begin{abstract}
To assess the effects of methylphenidate on working memory, pigeons were trained in a delayed matching-to-sample task. Delay interval duration $(0.2,1,3,6$, or $12 \mathrm{sec})$ was varied within sessions in order to separate delay-dependent from delay-independent effects of the drug on performance. A reduction in the sample response requirement from five responses to one response effectively reduced attention to the stimulus and impaired overall accuracy. Methylphenidate was administered in doses of 0.0 (saline control), $0.25,2.5$, and $10 \mathrm{mg} / \mathrm{kg}$. Relative to performance with saline, accuracy was significantly reduced with $10 \mathrm{mg} / \mathrm{kg}$ methylphenidate to the same extent in both fixed ratio (FR) 1 and FR 5 conditions. The smaller doses had no effect, and there was no evidence that accuracy improved with drug administration. Intercepts and slopes of exponential functions fitted to measures of discriminability plotted as a function of delay showed that methylphenidate affected delay-independent aspects of performance (initial discriminability), but not delay-dependent aspects (rate of forgetting).
\end{abstract}

The stimulant drug methylphenidate (MPH, marketed as Ritalin) is commonly used to treat attention deficit hyperactivity disorder (ADHD) in children at doses of $0.3-1.0 \mathrm{mg} / \mathrm{kg}$ (Solanto, 1998). At therapeutic doses, MPH significantly increases levels of extracellular dopamine in the brain by blocking the dopamine transporter, thus preventing the neurotransmitter's removal (Volkow et al., 2001). MPH also facilitates the release of both dopamine and norepinephrine (Solanto, 1998). Both dopamine and norepinephrine are involved in processes of attention, learning, and memory (Gallagher \& Rapp, 1997; Puumala \& Sirvio, 1998; Ragozzino, 2000; Robbins \& Everitt, 1995; Wolkowitz, Tinklenberg, \& Weingartner, 1985). MPH is therefore expected to influence attention and memory.

Consistent with its effects on dopamine and norepinephrine, MPH improves performance on tasks requiring attention, with many studies focusing on its effects in children. For example, in tasks requiring sustained attention, $0.4 \mathrm{mg} / \mathrm{kg} / \mathrm{day}$ of MPH reduced errors of omission by children with subaverage IQs (Aman, Marks, Turbott, Wilsher, \& Merry, 1991), and 10, 15, and $20 \mathrm{mg}$ reduced errors of omission by children with ADHD and/or mood disorder (Rapport, Carlson, Kelly, \& Pataki, 1993).

$\mathrm{MPH}$ has also been found to improve working memory. For example, Rapport et al. (1993) reported that MPH $(10,15$, and $20 \mathrm{mg})$ increased the number of associations

We thank Chanelle Cummings, Karin Ludwig, Sarah O’Neill, Angela Ruske, and Rebecca Sargisson for their helpful assistance during the conduct of this study, Barry Dingwall and his team for their technical support, and Rhonda Rosengren for her assistance in the preparation of the drug. Correspondence concerning this article should be addressed to K. G. White, Department of Psychology, University of Otago, Dunedin, New Zealand (e-mail: kgwhite@psy.otago.ac.nz). between pairs of letters and numbers that were correctly learned by children with ADHD or mood disorder in a 15min period. The effect of MPH on memory is not always consistent, however, even within studies. Mehta et al. (2000) found that, administered to healthy adult males, MPH (40 mg) significantly reduced search errors of one type, but not of another, in a spatial working memory task. Similarly, $20 \mathrm{mg}$ MPH improved healthy young adults' learning of lists of difficult words presented aurally but did not improve free recall of easy words presented visually (Camp-Bruno \& Herting, 1994). Aman et al. (1991) found that MPH $(0.4 \mathrm{mg} / \mathrm{kg} /$ day $)$ improved the accuracy of children with subaverage IQs on a delayed matchingto-sample task but did not affect their performance in another working memory task, which required them to indicate whether a picture was a member of an earlier presented array.

Anecdotal reports indicate that MPH can attenuate the memory deficits of AD patients (see, e.g., Kittur \& Hauser, 1999). However, experimental results have been equivocal. Galynker et al. (1997) found that MPH (10-20 mg/day) improved the scores of 12 patients with $\mathrm{AD}$ and 15 with vascular dementia on the Mini-Mental State Examination, which assesses a variety of cognitive functions, including recall of recently presented words (Folstein, Folstein, \& $\mathrm{McHugh}$, 1975). However, this improvement was not statistically significant for the AD patients when the results of the two groups were analyzed separately. In 12 elderly subjects who experienced cognitive and memorial problems greater than those typically associated with normal aging, although they were not diagnosed as having AD, Crook, Ferris, Sathananthan, Raskin, and Gershon (1977) found no effect of MPH (10, 30, and $45 \mathrm{mg})$ on tests of learning and memory. Their tasks included the learning of relations between symbols, visual recognition mem- 
ory, immediate rote memory of digits, learning and recall of paired associates, and the immediate and delayed recall of verbal information.

Not only have observed facilitative effects of MPH been inconsistent both within and between studies, but MPH and other stimulant drugs have also had negative effects in other studies. For example, cocaine $(10-18 \mathrm{mg} / \mathrm{kg}$ ) and $d$-amphetamine $(1.0-3.0 \mathrm{mg} / \mathrm{kg}$ ) impaired rats' performance on delayed spatial alternation and matchingto-position tasks (Baron, Wright, \& Wenger, 1998; Dunnett, 1985; Kesner, Bierley, \& Pebbles, 1981), and $d$-amphetamine $(0.56-1.0 \mathrm{mg} / \mathrm{kg})$ and quinpirole $(0.018$ $0.056 \mathrm{mg} / \mathrm{kg}$ ) impaired rats' delayed nonmatching-toposition (Bushnell \& Levin, 1993). Bartus (1978) examined the effect of MPH on delayed matching-to-sample in monkeys with varied retention interval duration and found that the drug impaired performance. Bartus (1978) initially decreased accuracy by administering scopolamine. This drug decreases cholinergic activity and impairs memory by reducing initial discriminability without affecting rate of forgetting (Kirk, White, \& McNaughton, 1988). Bartus (1978) found that when monkeys' delayed matching-to-sample performance was already impaired by scopolamine, $0.0125 \mathrm{mg} / \mathrm{kg}$ MPH produced a further impairment. It had no effect, however, on baseline performance. Therefore, it is possible that the increase in the scopolamine-induced deficit with MPH administration was due to a drug interaction. It is also possible that administration of injections disrupted the animals' performance, although, because a vehicle control condition was not included, this cannot be assessed.

Therefore, the results of some studies have indicated that MPH may improve performance in memory tasks, whereas the results of others have indicated that it may impair performance. But because retention interval was not systematically varied in the tasks, it is not possible to identify whether delay-dependent or delay-independent components of memory were affected. By varying the duration of the retention interval, delay-independent effects (i.e., effects on initial discriminability-discriminability at zero delay) are able to be separated from delay-dependent effects (i.e., effects on the rate of forgetting; White, Ruske, \& Colombo, 1996). For example, both empirical research with AD patients (Money, Kirk, \& McNaughton, 1992) and a quantitative reanalysis of the results of several studies on working memory in both early and late stages of AD have shown that initial discriminability, rather than rate of forgetting, is impaired (White \& Ruske, 2002). It has been suggested that attentional deficits during encoding underlie this type of impairment (Bushnell \& Levin, 1993; Parkes \& White, 2000).

In the present study, a nonpharmacological manipulation was used to effectively impair attention during the encoding component of memory in delayed matching-tosample. When a bird pecks the sample stimulus in this procedure and the pecks function as observing responses, it is attending to it (Dinsmoor, 1985). Therefore, attentional impairments can be generated by reducing the number of responses a bird must make to the sample stimulus before the delay begins (Roberts, 1972). Previous research has shown that this manipulation reduces initial discriminability but does not affect rate of forgetting and that this encoding deficit is sensitive to drug effects (Parkes \& White, 2000). In light of the conflicting effects of MPH in previous studies, the purpose of the present experiment was to examine the effects of MPH in a laboratory task on both (nonpharmacologically) impaired and unimpaired baseline levels of performance. Therefore, the effects of MPH were examined both in a condition in which five sample responses were required on each trial and in a condition in which only one response was required. The retention interval in the delayed matching-to-sample task was varied within sessions, allowing differentiation of the delay-dependent and the delay-independent effects of the attentional manipulation and of MPH. Doses of 0.0 (vehicle control) and $0.25 \mathrm{mg} / \mathrm{kg}$ were administered, as well as doses of 2.5 and $10 \mathrm{mg} / \mathrm{kg}$, which correspond to low and moderate doses, respectively (Brandon, Marinelli, Baker, $\&$ White, 2001). These doses of MPH are representative of the range used in previous research with pigeons and rats (see the Appendix).

If MPH improves attention, as has been indicated by previous research, one possible outcome of the present experiment would be an alleviation of the impairment produced when only one response to the sample was required. That is, an interaction between drug dose and fixed ratio (FR) requirement would be expected. If, however, MPH impairs memory, as has been indicated by the results of other studies, impaired performance in both FR conditions would be expected. Indeed, this was the result of the present experiment.

\section{METHOD}

\section{Subjects}

Subjects were 5 pigeons (Columba livia) with prior experience in delayed matching-to-sample. The birds were housed under an approximately 12:12-h light:dark cycle in individual cages $(41 \mathrm{~cm}$ wide, $41 \mathrm{~cm}$ deep, and $44 \mathrm{~cm}$ high). Water and grit were always available in the cages. Daily feeding after experimental sessions maintained the pigeons at $85 \% \pm 10 \mathrm{~g}$ of their free-feeding weight. Ethical approval was covered by AEC 1/01 from the University of Otago.

\section{Apparatus}

Experimental sessions were conducted in MedLab Associates operant chambers. The chambers were $35.5 \mathrm{~cm}$ wide, $32 \mathrm{~cm}$ deep, and $30 \mathrm{~cm}$ high. On one wall were three circular response keys, $2.5 \mathrm{~cm}$ in diameter, positioned $8 \mathrm{~cm}$ apart and $22 \mathrm{~cm}$ from the wire grid floor. The keys could be illuminated red or green. An opening $5.3 \mathrm{~cm}$ high, $6 \mathrm{~cm}$ wide, and $4.5 \mathrm{~cm}$ deep was positioned below the center key, $3 \mathrm{~cm}$ from the floor. To deliver reinforcers, a hopper could be raised behind the opening, allowing access to grain. The hopper was illuminated during reinforcer delivery. A ventilation fan masked extraneous noise in the room, and apart from the hopper- and keylights, the chambers were in complete darkness during sessions. Med-PC for Windows software (Version 1.15) on PC computers in an adjacent room controlled and recorded experimental events.

\section{Procedure}

Experimental sessions were conducted 7 days per week at about 11 a.m. each morning (the light cycle began at 7 a.m.). Sessions lasted for either 80 trials or $50 \mathrm{~min}$, whichever limit was reached 
first. A trial began with the illumination of the center key either green or red (the sample stimulus). In different experimental conditions, the pigeon was required to peck the lit center key five times (an FR 5 response requirement) or once (FR 1) in order to extinguish the light and initiate a delay interval, during which the chamber was in darkness. Delays varied over 0.2, 1, 3, 6, and $12 \mathrm{sec}$ within each session. After the delay, both side keys were illuminated, one red and the other green (the comparison stimuli). A single response to the comparison stimulus, which matched the sample stimulus, produced 3 -sec access to grain, followed by a 15 -sec intertrial interval, during which the chamber was dark. A single response to the nonmatching stimulus produced $3 \mathrm{sec}$ of darkness before the intertrial interval.

For each sample color (red and green), the matching comparison stimulus could be presented on either the left or the right side key. These four sample-comparison configurations were combined with the five delays to give 20 different possible trials. The 20 trials were repeated four times per session in a quasirandom order, with the constraint that half of the time the sample stimuli of consecutive trials were the same and half of the time they were different. In each session, the numbers of correct and error responses made to each of the red and green sample stimuli at each delay were recorded for each bird. The birds were trained in the delayed matching-to-sample procedure with the FR 5 response requirement for 59 sessions before the beginning of the first drug administration phase. There were four phases of drug administration (see Table 1). The first and fourth phases used the FR 5 response requirement, and the second and third phases used the FR 1 response requirement. This counterbalanced order controlled for potential changes in performance across time. The two FR 1 phases were preceded by 13 and 5 sessions, respectively, of baseline training in delayed matching-tosample with the FR 1 response requirement. The fourth phase, with the FR 5 response requirement, was preceded by 12 sessions of baseline training with FR 5. Performance in baseline training preceding each phase was stable, as is demonstrated by the overlap of the functions plotting discriminability against retention interval for the last 4 sessions and the absence of a statistically significant difference when the data from the 2 sessions immediately preceding each phase were compared with the data from the 2 sessions immediately before them.
The birds were weighed before each session. On days with baseline sessions - that is, all days on which injections were not administeredany bird that was more than $10 \mathrm{~g}$ above or below $85 \%$ of its freefeeding weight was not run in the session. On days on which injections were administered, all the birds were run regardless of weight.

\section{Drug Administration}

Methylphenidate was obtained in the form of Ritalin tablets, from which the excipients were removed, and the pure drug was extracted and prepared for injection in saline vehicle, through processes of centrifugation and filtration. During phases of drug administration, sessions continued to be run daily, with injections given four times per week. Nominal doses of MPH were $0.0,0.25,2.5$, and $10 \mathrm{mg} / \mathrm{kg}$. Actual doses were $0.0,0.244,2.44$, and $9.76 \mathrm{mg} / \mathrm{kg}$. These were administered via intraperitoneal injection. Injections were $1.22 \mathrm{ml} / \mathrm{kg}$ in volume. During each drug phase, doses were administered twice, in order of increasing, then decreasing, strength. As with FR response requirement conditions, the ABBA order of dose administration within each phase controlled for possible order effects. There were at least $48 \mathrm{~h}$ between doses, assumed to be an ample washout period, since Gerasimov et al. (2000) had observed that the dopamine levels of rats returned to baseline $140 \mathrm{~min}$ after intraperitoneal administration of 5- and $10-\mathrm{mg} / \mathrm{kg}$ doses of MPH. On the basis of the results reported by Gerasimov et al., injections were given $30 \mathrm{~min}$ before the beginning of experimental sessions.

\section{Data Analysis}

For analysis, each bird's data were summed across the four sessions at each dose in each response requirement condition. For initial analyses of the effects of FR response requirement, dose, and delay on accuracy, proportion correct was calculated by dividing the total number of correct responses by the total number of correct and error responses. Proportion correct measures were submitted to an analysis of variance for repeated measures on the three factors of FR response requirement, dose, and delay. The significance level was set at $p=.05$, and post hoc analyses used Duncan's multiple range test.

Because proportion correct is bounded at 1.0, it is susceptible to ceiling effects and is insensitive to small variations in performance when accuracy is high overall. It is also susceptible to response bias. Thus, it is not an appropriate measure for the purpose of fitting

Table 1

Order of Experimental Conditions, With Sample Response Requirements of Five

(FR 5) or One (FR 1) and Different Dose Levels of Methylphenidate (MPH), Identified by Session Number

\begin{tabular}{lll}
\hline Phase & \multicolumn{1}{c}{ Condition } & \multicolumn{1}{c}{ Session Number } \\
\hline One & FR 5, baseline & $1-60,62,64,66,68-69,71,73,75$ \\
& FR 5, 0.0 mg/kg MPH & 61,76 \\
& FR 5, 0.25 mg/kg MPH & 63,74 \\
& FR 5, 2.5 mg/kg MPH & 65,72 \\
& FR 5, 10.0 mg/kg MPH & 67,70 \\
Two & FR 1, baseline & $77-88,90,92,94,96-97,99,101,103$ \\
& FR 1, 0.0 mg/kg MPH & 89,104 \\
& FR 1, 0.25 mg/kg MPH & 91,102 \\
& FR 1, 2.5 mg/kg MPH & 93,100 \\
& FR 1, 10.0 mg/kg MPH & 95,98 \\
Three & FR 1, baseline & $105-109,111,113,115,117-118,120,122,124$ \\
& FR 1, 0.0 mg/kg MPH & 110,125 \\
& FR 1, 0.25 mg/kg MPH & 112,123 \\
& FR 1, 2.5 mg/kg MPH & 114,121 \\
& FR 1, 10.0 mg/kg MPH & 116,119 \\
Four & FR 5, baseline & $126-137,139,141,143,145-146,148,150,152$ \\
& FR 5, 0.0 mg/kg MPH & 138,153 \\
& FR 5, 0.25 mg/kg MPH & 140,151 \\
& FR 5, 2.5 mg/kg MPH & 142,149 \\
& FR 5, 10.0 mg/kg MPH & 144,147 \\
\hline
\end{tabular}


mathematical functions to the data (White, 2001). Subsequent analyses therefore used $\log d$, an unbiased measure of discriminability that is based on Luce's (1963) choice theory and is linearly related to $d^{\prime}$ of signal detection theory (MacMillan \& Creelman, 1991). $\log d$ was calculated from $\log$ (base 10) of the ratio of correct to error responses to each of the red and green stimuli. To avoid divisors of zero, 0.5 was first added to each total of correct responses following red and green samples $\left(c_{\mathrm{r}}, c_{\mathrm{g}}\right)$ and error responses following red and green samples $\left(e_{\mathrm{r}}, e_{\mathrm{g}}\right.$; Hautus, 1995). The discriminability measure is given by

$$
\log d=0.5 \log \left[\left(c_{\mathrm{r}} / e_{\mathrm{r}}\right)\left(c_{\mathrm{g}} / e_{\mathrm{g}}\right)\right] .
$$

For each bird at each dose with each FR response requirement, forgetting functions were constructed by plotting $\log d$ against delay $(t)$ and by fitting negative exponential functions, with time scaled to the square root (White, 2001), to the data, using the nonlinear least-squares regression method provided by SigmaPlot software (Version 5.0). The function is given by

$$
\log d=a * \exp (-b * \sqrt{t})
$$

The slope, $b$, gives an estimate of rate of forgetting, and the intercept, $a$, represents initial discriminability. The parameters estimate the delay-dependent and the delay-independent characteristics of the forgetting functions (White, 1985, 2001). The intercepts and slopes of the forgetting functions were submitted to repeated measures analyses of variance to assess the effects of FR response requirement and dose on initial discriminability and rate of forgetting.

\section{RESULTS}

In each session, correct and error responses by each bird in trials with red and green samples were summed separately at each delay, with a total of 16 trials ( 8 red and 8 green) at each delay. These data were then summed over the four sessions with each dose for each FR response requirement. All subsequent analyses are based on these total frequencies. Bird F5 failed to complete any trials in three of the four FR 5 sessions with $10 \mathrm{mg} / \mathrm{kg} \mathrm{MPH}$ and, in the fourth session, completed only 26 . Bird F5's data for this condition were, therefore, based on a smaller number of trials. This result was not considered a problem, however, because results from the 26 completed trials were consistent with those for the other birds in this condition. Similarly, Bird F2 failed to complete any trials in the first FR 5 saline session, and so data from an earlier (preliminary) saline session (Session 49) were substituted. Baseline data were taken from the two sessions conducted by each bird immediately prior to the beginning of each of the four drug administration phases. A repeated measures analysis of variance confirmed that the proportion of correct responses did not differ between saline and baseline sessions.

Figure 1 (left panels) shows that the proportion of correct responses decreased systematically with increasing delay and was, overall, lower with the smaller FR response requirement. Figure 1 (right panels) shows that the proportion of correct responses (collapsed across delay) decreased with the highest dose of MPH, although accuracy with the two smaller doses was little different from that with saline control. Figure 1 shows that the effects of drug dose, FR response requirement, and delay were consistent across individual birds. The dose functions for individual birds (Figure 1, right panels) are virtually parallel for the FR 5 and the FR 1 conditions.

The above conclusions were confirmed by an analysis of variance for repeated measures on the factors of FR response requirement, dose, and delay. The effects of FR response requirement $[F(1,4)=88.14]$, dose $[F(3,12)=$ $18.53]$, and delay $[F(4,16)=78.89]$ on proportion correct were statistically significant. There were no significant interactions between any of the factors.

The main effect of dose (Figure 1, right panels) was further examined with a Duncan's multiple range test.

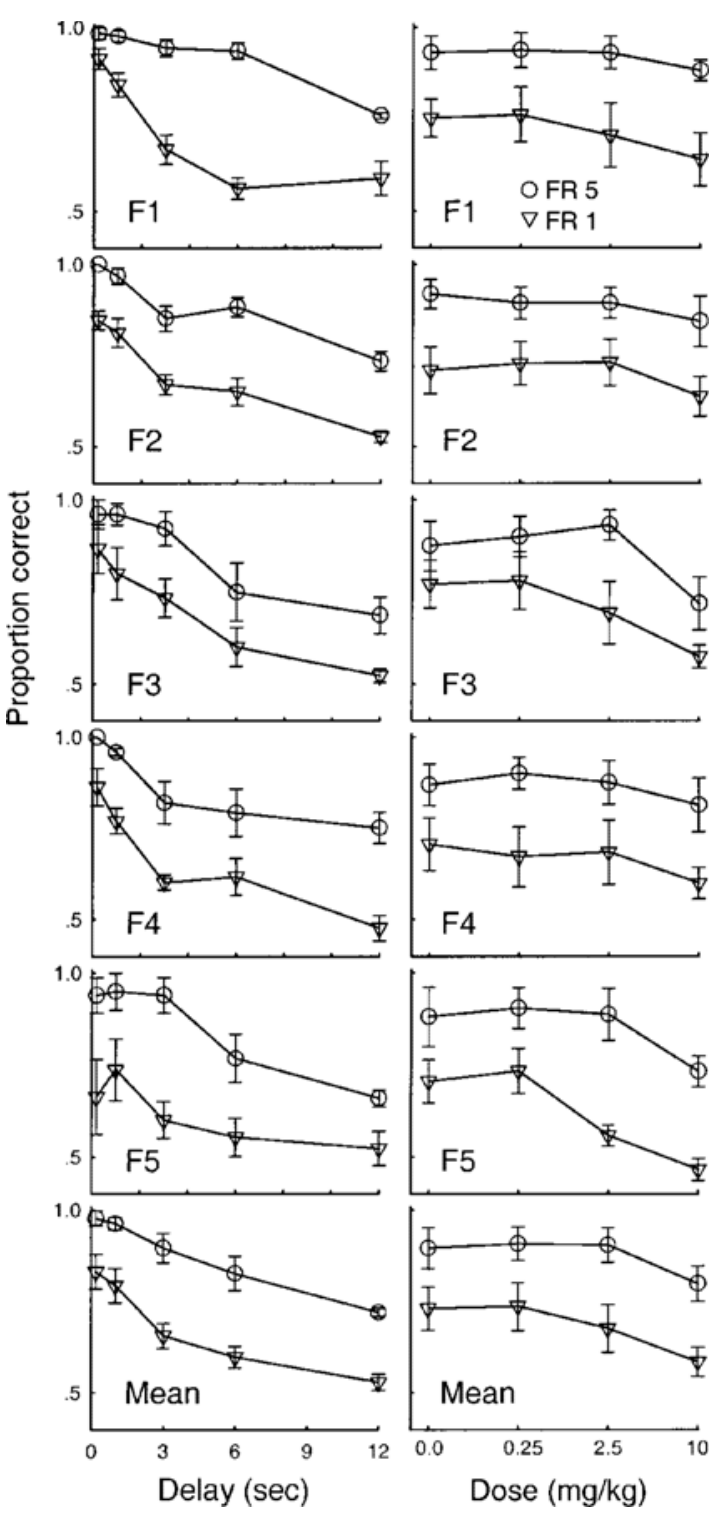

Figure 1. Mean proportion of correct responses averaged across doses as a function of delay and fixed ratio (FR) response requirement (left panels) and mean proportion correct averaged across delays as a function of dose of methylphenidate and FR response requirement (right panels) for individual birds and for the means across birds. Vertical lines depict standard errors of the means. 
Accuracy at the smaller doses of 0.25 and $2.5 \mathrm{mg} / \mathrm{kg}$ was not significantly different from accuracy with saline or from each other. However, accuracy with the $10-\mathrm{mg} / \mathrm{kg}$ dose was significantly lower than accuracy with each other dose (Duncan's $p<.05$ ).

Figure 2 shows that discriminability $(\log d)$ decreased with increasing delay interval duration and was, overall, lower with the FR 1 than with the FR 5 response requirement. The decrement in performance caused by $10 \mathrm{mg} / \mathrm{kg}$ MPH is clearly shown in Figure 2.

Figure 2 also shows the best-fitting exponential functions fitted to the $\log d$ measures for individual birds and to the $\log d$ measures averaged across birds. Table 2 gives the values of the intercept and slope parameters and the variance accounted for by the best-fitting exponential functions. Figure 3 shows the parameter values, averaged across birds. The parameter values summarize the entire forgetting function (discriminability plotted as a function of delay). Figure 3 (left panel) clearly shows that initial discriminability (intercept, $a$ ) was higher with the FR 5 than with the FR 1 response requirement at all doses. With both FR response requirements, initial discriminability decreased with $10 \mathrm{mg} / \mathrm{kg}$, relative to saline. A repeated measures analysis of variance confirmed the significant main effects of FR response requirement $[F(1,4)=27.51]$ and dose $[F(3,12)=8.03]$ on initial discriminability. The interaction between FR response requirement and dose was not significant. Post hoc analyses showed that initial discriminability with the $10-\mathrm{mg} / \mathrm{kg}$ dose was significantly lower than that with saline and with the two other doses (Duncan's $p<.05$ ). There were no significant differences between the effects of saline, $0.25 \mathrm{mg} / \mathrm{kg} \mathrm{MPH}$, and $2.5 \mathrm{mg} / \mathrm{kg} \mathrm{MPH}$.

Figure 3 (right panel) shows that the rate of forgetting (slope, $b$ ) remained stable across all drug doses. However, there was a slight increase in rate of forgetting with the FR 1 response requirement, relative to FR 5. Analysis of variance confirmed this effect of FR response requirement on rate of forgetting $[F(1,4)=17.96]$, but there was no significant effect of drug dose and no significant interaction with dose.

Occasionally, the birds failed to complete sessions. This was almost exclusive to FR 5 sessions and occurred in both baseline and drug sessions. There was no consistent relationship between the failure to complete sessions and drug dose or administration of injections, although the failure to complete sessions occurred only during phases of drug administration.

Owing to the design of the present experiment, order effects were controlled for. When the discriminability measures were submitted to an analysis of variance that included replication as a factor, accuracy in the replications of the two FR conditions was overall lower than that in the first presentation of the conditions $[F(1,4)=$ $8.44]$. The effect of dose (including $0.0 \mathrm{mg} / \mathrm{kg}$ ) was the same for the two replications, however, and there was no statistically significant interaction between dose and replication $[F(3,12)<1]$. Therefore, this change cannot be attributed to sensitization or tolerance to the drug.
FR 5 FR 1

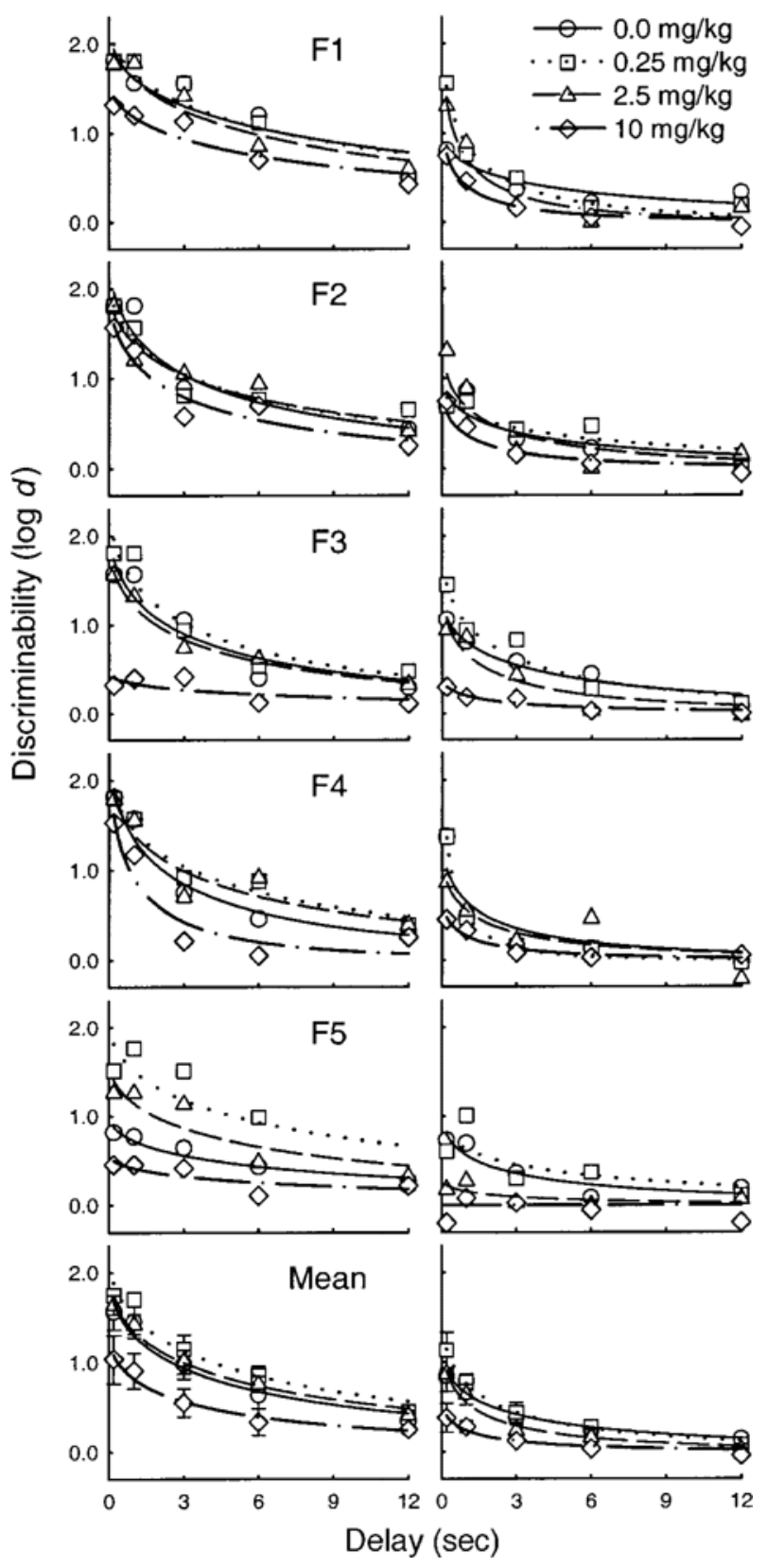

Figure 2. Discriminability as a function of delay with different doses of methylphenidate, and fixed ratio (FR) 1 versus FR 5 sample response requirements. Smooth curves are best-fitting negative exponential functions with time scaled to $\sqrt{ } t$.

After 4 months of continued training in the same procedure following completion of the fourth phase, a further condition was added in order to examine the effect of a $1.64-\mathrm{mg} / \mathrm{kg}$ dose of MPH. This dose is approximately equivalent in pigeons to a $0.43-\mathrm{mg} / \mathrm{kg}$ dose in humans (Gibbons, Pokras, \& Sedgwick, 1988), which is within the therapeutic dose range (Solanto, 1998). Over a total of 26 sessions, including baseline sessions, the pigeons 
Table 2

Parameters of the Least-Squares Fits of Exponential Functions to the $\log d$ Measures for Individual Birds and Averaged Across Birds (Mean) in FR 5 and FR 1 Conditions and the Variance Accounted for (VAC) by the Best-Fitting Functions

\begin{tabular}{|c|c|c|c|c|c|c|c|}
\hline \multirow[b]{2}{*}{ Dose MPH } & \multirow[b]{2}{*}{ Bird } & \multicolumn{3}{|c|}{ FR 5} & \multicolumn{3}{|c|}{ FR 1} \\
\hline & & $a$ & $b$ & VAC & $a$ & $b$ & VAC \\
\hline \multirow[t]{6}{*}{$0.0 \mathrm{mg} / \mathrm{kg}$} & $\mathrm{F} 1$ & 2.170 & 0.292 & 0.827 & 1.068 & 0.481 & 0.796 \\
\hline & F2 & 2.443 & 0.491 & 0.911 & 1.064 & 0.571 & 0.775 \\
\hline & F3 & 2.193 & 0.513 & 0.882 & 1.382 & 0.541 & 0.955 \\
\hline & F4 & 2.538 & 0.635 & 0.959 & 1.459 & 0.816 & 0.949 \\
\hline & F5 & 1.026 & 0.347 & 0.915 & 1.044 & 0.620 & 0.861 \\
\hline & $M$ & 2.041 & 0.448 & 0.958 & 1.195 & 0.600 & 0.940 \\
\hline \multirow[t]{6}{*}{$0.25 \mathrm{mg} / \mathrm{kg}$} & $\mathrm{F} 1$ & 2.306 & 0.316 & 0.851 & 2.392 & 0.100 & 0.973 \\
\hline & F2 & 2.198 & 0.426 & 0.913 & 0.960 & 0.445 & 0.743 \\
\hline & F3 & 2.478 & 0.512 & 0.902 & 1.961 & 0.667 & 0.943 \\
\hline & F4 & 2.265 & 0.448 & 0.956 & 3.016 & 1.781 & 0.990 \\
\hline & F5 & 2.117 & 0.336 & 0.699 & 0.981 & 0.441 & 0.547 \\
\hline & $M$ & 2.249 & 0.396 & 0.945 & 1.599 & 0.737 & 0.995 \\
\hline \multirow[t]{6}{*}{$2.5 \mathrm{mg} / \mathrm{kg}$} & $\mathrm{F} 1$ & 2.262 & 0.340 & 0.904 & 2.281 & 1.154 & 0.937 \\
\hline & $\mathrm{F} 2$ & 2.069 & 0.401 & 0.921 & 1.486 & 0.786 & 0.989 \\
\hline & F3 & 2.024 & 0.511 & 0.977 & 1.508 & 0.819 & 0.883 \\
\hline & $\mathrm{F} 4$ & 2.250 & 0.475 & 0.888 & 1.244 & 0.816 & 0.727 \\
\hline & F5 & 1.681 & 0.384 & 0.811 & 0.309 & 0.709 & 0.513 \\
\hline & $M$ & 2.045 & 0.414 & 0.985 & 1.347 & 0.886 & 0.973 \\
\hline \multirow[t]{6}{*}{$10 \mathrm{mg} / \mathrm{kg}$} & $\mathrm{F} 1$ & 1.619 & 0.315 & 0.891 & 1.292 & 1.154 & 0.977 \\
\hline & F2 & 2.057 & 0.551 & 0.919 & 0.952 & 0.958 & 0.991 \\
\hline & F3 & 0.464 & 0.310 & 0.519 & 0.432 & 0.779 & 0.907 \\
\hline & F4 & 2.552 & 1.031 & 0.897 & 0.753 & 1.032 & 0.940 \\
\hline & F5 & 0.584 & 0.339 & 0.651 & 0.000 & 0.000 & 0.000 \\
\hline & $M$ & 1.360 & 0.504 & 0.971 & 0.628 & 0.967 & 0.945 \\
\hline
\end{tabular}

were administered 0.0 and $1.64 \mathrm{mg} / \mathrm{kg} \mathrm{MPH}$ twice in both FR 1 and FR 5 conditions. The results were analyzed as above, and there was no significant main effect of dose and no interactions with dose.

\section{DISCUSSION}

The aim of the present study was to assess the effect of MPH on working memory performance. There was no evidence that MPH could alleviate an encoding deficit caused by reducing the sample response requirement from five responses to one. Instead, MPH decreased ac- curacy at the highest dose of $10 \mathrm{mg} / \mathrm{kg}$, in both impaired (FR 1) and nonimpaired (FR 5) conditions. The present analysis showed that MPH influenced memory through an effect on initial discriminability, rather than on rate of forgetting. Rate of forgetting did not change across doses, whereas initial discriminability in both FR 5 and FR 1 conditions was decreased by $10 \mathrm{mg} / \mathrm{kg} \mathrm{MPH}$. The effect of MPH on initial discriminability is consistent with an effect on the attentional component of working memory performance (White \& Ruske, 2002), although it was an impairment in both FR conditions, and not the beneficial effect that would be expected in the FR 1 con-
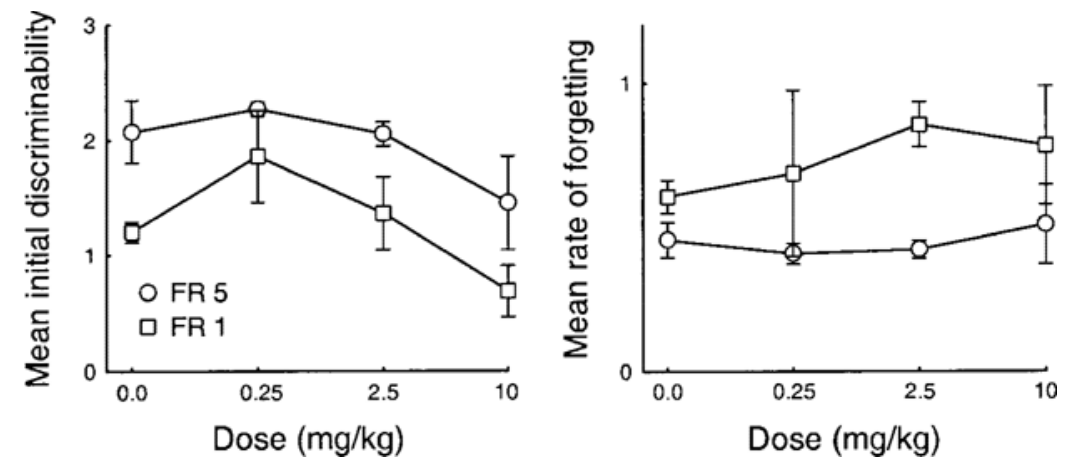

Figure 3. Mean values of parameters for initial discriminability (left panel) and rate of forgetting (right panel) for the best-fitting functions in Figure 2, as a function of dose of methylphenidate with fixed ratio (FR) 1 and F 5 response requirements. Vertical lines depict standard errors of the means. 
dition according to studies that have claimed a beneficial effect of MPH on attention (Aman et al., 1991; Rapport et al., 1993).

It is possible that the apparent inconsistency between the present results and those in studies that have found that MPH improved memory in humans (Aman et al., 1991; Camp-Bruno \& Herting, 1994; Galynker et al., 1997; Mehta et al., 2000; Rapport et al., 1993) is due to species differences between samples. However, the dopaminergic systems of pigeons and mammals are highly similar (Karle, Anderson, Medina, \& Reiner, 1996), and the neostriatum caudolaterale of pigeons is believed to be equivalent to the mammalian prefrontal cortex (Hartmann \& Gunturkun, 1998), an area that is involved in memory, attention, and the effects of MPH (Mehta et al., 2000; Puumala \& Sirvio, 1998; Ragozzino, 2000). Furthermore, other drugs have had similar effects on primates and pigeons (White et al., 1996). Therefore, it is unlikely that the choice of species is the reason the present study failed to show a facilitatory effect of MPH on memory.

The absence of an effect of small doses of MPH on working memory in the present study is consistent with the results of several prior studies. Galynker et al. (1997) found no effect of MPH on the memory of AD patients, and Crook et al. (1977) found no effect of the drug on memory in an elderly sample. It is possible that the reason these samples did not show an effect of MPH is that the drug's efficacy in increasing dopamine availability decreases with age (Volkow et al., 2001). However, this cannot explain the failure of some studies to show effects of MPH on the working memory of children. Winsberg, Kupietz, Sverd, Hungund, and Young (1982) found no effect of $0.25,0.5$, or $1.0 \mathrm{mg} / \mathrm{kg}$ MPH on the accuracy of children with ADHD in a picture recognition task. Likewise, Douglas, Barr, Amin, O’Neill, and Britton (1988) found no effect of $0.15,0.3$, or $0.6 \mathrm{mg} / \mathrm{kg} \mathrm{MPH}$ on children's learning of paired associates. Furthermore, Thompson (1976) reported that $2.5 \mathrm{mg} / \mathrm{kg} \mathrm{MPH}$ had no effect on pigeons' learning of behavioral chains.

Although small doses of MPH did not affect working memory in the present experiment, the higher dose of $10 \mathrm{mg} / \mathrm{kg}$ significantly decreased delayed matching-tosample accuracy. This is consistent with the results of other studies. Mayorga, Popke, Fogle, and Paule (2000) found that at doses of $4.5 \mathrm{mg} / \mathrm{kg}$ and higher, MPH decreased rats' accuracy in a learning task and in a conditional matching-to-sample task. Impairment of performance by MPH in their matching-to-sample task with no delay is consistent with the present finding that MPH affects memory by reducing initial discriminability, a delay-independent effect. Thompson $(1974,1976)$ found that doses of 5,10 , and $20 \mathrm{mg} / \mathrm{kg}$ increased errors by pigeons when they were learning behavioral chains. Similarly, Bartus (1979) administered 0.1, 0.2, 0.4, and $0.8 \mathrm{mg} / \mathrm{kg} \mathrm{MPH}$ to monkeys and found that the two higher doses significantly reduced delayed matching-to-sample accuracy.

Although responses to specific doses may vary across species, there is a consistent trend for small doses of
MPH to have no effect on memory and for larger doses to have a deleterious effect. This is consistent with the conclusion that there is an optimal range of activation of the dopamine and norepinephrine systems for the facilitation of working memory. Both under- and overstimulation of these neurotransmitter systems can impair performance on memory tasks (Bushnell \& Levin, 1993; Ragozzino, 2000; Rajkowski, Kubiak, \& Aston-Jones, 1992).

The manifestation of the MPH-induced memory deficit in the present study as a reduction in initial discriminability suggests an effect on the encoding or attentional component of memory. An alternative explanation, however, is that MPH influenced the motor component of performance. Although stimulants sometimes impair memory performance without an effect on indices of motor behavior (Baron et al., 1998; Bushnell \& Levin, 1993; Kesner et al., 1981), Beatty and Rush (1983) argued that the $d$-amphetamine-induced deficit in a radial arm maze memory task was due to motor rather than cognitive drug effects on their rats. If MPH resulted in longer choice latencies in the present study, the effective increase in retention interval would generate reduced accuracy. Therefore, an additional analysis was conducted on the latencies to choice responses in all drug administration sessions in Phases 1-4. There was a main effect of dose on response latency $[F(3,12)=8.10]$ but no main effect of FR condition, and there were no interactions with dose. Post hoc comparisons showed that response latencies were significantly shorter with the two highest doses, relative to saline. Therefore, there was no support for the possibility that MPH reduced accuracy by lengthening retention interval duration. Instead, reduced accuracy coincided with shorter response latencies. This is consistent with other studies in which MPH has increased activity levels, stereotypic movements, and response rates and has decreased response latency (Eckerman, Segbefia, Manning, \& Breese, 1987; Gaytan, al-Rahim, Swann, \& Dafny, 1997; Gaytan, Sripada, Swann, \& Dafny, 2001; Poncelet, Chermat, Soubrie, \& Simon, 1983; Thompson, 1974) and is analogous to a speed-accuracy tradeoff.

The results of both the present experiment and the previous studies summarized above are inconsistent with the results of other studies in which MPH has been shown to improve working memory. However, the evidence offered by most of the studies reporting improvements is not convincing. It has been reported that within studies, MPH had an effect on one sample (Galynker et al., 1997; Prendergast et al., 1998), one type of working memory task (Aman et al., 1991; Camp-Bruno \& Herting, 1994), or one type of error (Mehta et al., 2000), but not on another. Camp-Bruno and Herting's report that MPH improved the learning of words, as compared with a placebo, was based on results that were significant at $p<.10$, which is usually considered not statistically significant. Prendergast et al. reported equivocal evidence for the reversal by MPH of a decrement in delayed matching-tosample performance caused by the interpolation of retroactive interference (houselight illumination) in the 
delay interval. For aged monkeys, there was no effect of MPH. For young monkeys, the proportion of correct responses at one of four delays with one of four interference conditions was higher with one of four doses of MPH $(0.125 \mathrm{mg} / \mathrm{kg})$ than with saline. The result for this single comparison, however, is difficult to interpret because, in baseline (nondrug) trials, accuracy at that one delay in that one condition was not consistent with accuracy at other delays in the same condition. In addition, accuracy in the critical vehicle control condition was anomalously lower than that in the corresponding noninjection baseline condition. Prendergast et al. also failed to report results for a saline-no-distraction condition, which is a necessary comparison for meaningful assessment of the effects of distraction and of the drug. It is not possible, therefore, to draw unequivocal conclusions from the study reported by Prendergast et al. In sum, evidence from previous studies for an alleviation in deficits in attention and memory by MPH administration is unconvincing.

The results of the present experiment are consistent with studies that have not supported a role for MPH in the improvement of memory, including the alleviation of memory deficits. There is, in fact, mounting evidence that, at certain doses, the drug significantly impairs performance on tasks requiring working memory. The present study has further demonstrated that the effect of MPH is due to changes in delay-independent aspects of working memory performance, without an influence on the retention of information.

\section{REFERENCES}

Aman, M. G., Marks, R. E., Turbott, S. H., Wilsher, C. P., \& Merry, S. N. (1991). Methylphenidate and thioridazine in the treatment of intellectually subaverage children: Effects on cognitive-motor performance. Journal of the American Academy of Child \& Adolescent Psychiatry, 30, 816-824.

BARON, S. P., WRight, D., \& Wenger, G. R. (1998). Effects of drugs of abuse and scopolamine on memory in rats: Delayed spatial alternation and matching to position. Psychopharmacology, 137, 7-14.

BARTUS, R. T. (1978). Evidence for a direct cholinergic involvement in the scopolamine-induced amnesia in monkeys: Effects of concurrent administration of physostigmine and methylphenidate with scopolamine. Pharmacology, Biochemistry \& Behavior, 9, 833-836.

BARTUS, R. T. (1979). Four stimulants of the central nervous system: Effects on short-term memory in young versus aged monkeys. Journal of the American Geriatrics Society, 27, 289-297.

BeAtTy, W. W., \& Rush, J. R. (1983). Retention deficit after $d$ amphetamine treatment: Memory defect or performance change? Behavioral \& Neural Biology, 37, 265-275.

Brandon, C. L., Marinelli, M., BAKer, L. K., \& White, F. J. (2001). Enhanced reactivity and vulnerability to cocaine following methylphenidate treatment in adolescent rats. Neuropsychopharmacology, 25, 651-661.

BushnELL, P. J., \& LEVIN, E. D. (1993). Effects of dopaminergic drugs on working and reference memory in rats. Pharmacology, Biochemistry \& Behavior, 45, 765-776.

CAmp-Bruno, J. A., \& Herting, R. L. (1994). Cognitive effects of milacemide and methylphenidate in healthy young adults. Psychopharmacology, 115, 46-52.

Carey, M. P., Diewald, L. M., Esposito, F. J., Pellicano, M. P., Carnevale, U. A. G., Sergeant, J. A., Papa, M., \& Sadile, A. G. (1998). Differential distribution, affinity and plasticity of dopamine
D-1 and D-2 receptors in the target sites of the mesolimbic system in an animal model of ADHD. Behavioural Brain Research, 94, 173-185.

Crook, T., Ferris, S., Sathananthan, G., Raskin, A., \& Gershon, S. (1977). The effect of methylphenidate on test performance in the cognitively impaired aged. Psychopharmacology, 52, 251-255.

DINSMOOR, J. A. (1985). The role of observing and attention in establishing stimulus control. Journal of the Experimental Analysis of Behavior, 43, 365-381.

Douglas, V. I., BARr, R. G., Amin, K., O’ NeILl, M. E., \& Britton, B. G. (1988). Dosage effects and individual responsivity to methylphenidate in attention deficit disorder. Journal of Child Psychology \& Psychiatry, 29, 453-475.

DunNETT, S. B. (1985). Comparative effects of cholinergic drugs and lesions of nucleus basalis or fimbria-fornix on delayed matching in rats. Psychopharmacology, 87, 357-363.

Eckerman, D. A., Segbefia, D., Manning, S., \& Breese, G. S. (1987). Effects of methylphenidate and $d$-amphetamine on timing in the rat. Pharmacology, Biochemistry \& Behavior, 27, 513-515.

Folstein, M. F., Folstein, S. E., \& McHugh, P. R. (1975). "Minimental state": A practical method for grading the cognitive state of patients for the clinician. Journal of Psychiatric Research, 12, 189-198.

Gallagher, M., \& RAPP, P. R. (1997). The use of animal models to study the effects of aging on cognition. Annual Review of Psychology, 48, 339-370.

Galynker, I., Ieronimo, C., Miner, C., Rosenblum, J., Vilkas, N., \& Rosenthal, R. (1997). Methylphenidate treatment of negative symptoms in patients with dementia. Journal of Neuropsychiatry \& Clinical Neuroscience, 9, 231-239.

Gatley, S. J., Meehan, S. M., Chen, R., Pan, D.-F., Schechter,M. D., \& DEWEY, S.L. (1996). Place preference and microdialysis studies with two derivatives of methylphenidate. Life Sciences, 58, PL 345-352.

Gaytan, O., Al-Rahim, S., Swann, A., \& DafNy, N. (1997). Sensitization to locomotor effects of methylphenidate in the rat. Life Sciences, 61, PL 101-107.

Gaytan, O., Sripada, S., Swann, A., \& Dafny, N. (2001). Blockade of sensitization to methylphenidate by MK-801: Partial dissociation from motor effects. Neuropharmacology, 40, 298-309.

Gerasimov, M. R., Franceschi, M., Volkow, N. D., Rice, O., SchifFER, W. K., \& DEWEY, S. L. (2000). Synergistic interactions between nicotine and cocaine or methylphenidate depend on the dose of dopamine transporter inhibitor. Synapse, 38, 432-437.

GibBons, G., PoKRas, M., \& SedGWICK, C. (1988). Allometric scaling in veterinary medicine. Australian Veterinary Practitioner, 18, 160-164.

Hartmann, B., \& Gunturkun, O. (1998). Selective deficits in reversal learning after neostriatum caudolaterale lesions in pigeons: Possible behavioral equivalencies to the mammalian prefrontal system. Behavioural Brain Research, 96, 125-133.

Hautus, M. J. (1995). Corrections for extreme proportions and their biasing effects on estimated values of $d^{\prime}$. Behavior Research Methods, Instruments, \& Computers, 27, 46-51.

Karle, E. J., Anderson, K. D., Medina, L., \& Reiner, A. (1996). Light and electron microscopic immunohistochemical study of dopaminergic terminals in the striatal portion of the pigeon basal ganglia using antisera against tyrosine hydroxylase and dopamine. Journal of Comparative Neurology, 369, 109-124.

Kesner, R. P., BieRley, R. A., \& PeBbles, P. (1981). Short-term memory: The role of $d$-amphetamine. Pharmacology, Biochemistry \& Behavior, 15, 673-676.

Kirk, R. C., White, K. G., \& McNaughton, N. (1988). Low dose scopolamine affects initial discriminability but not rate of forgetting in delayed conditional discrimination. Psychopharmacology, 96, 541-546.

KitTUR, S., \& HAUSER, P. (1999). Improvement of sleep and behavior by methylphenidate in Alzheimer's disease. American Journal of Psychiatry, 156, 1116-1117.

Kline, A. E., Yan, H. Q., BaO, J., Marion, D. W., \& Dixon, C. E. (2000). Chronic methylphenidate treatment enhances water maze performance following traumatic brain injury in rats. Neuroscience Letters, 280, 163-166.

LucE, R. D. (1963). Detection and recognition. In R. D. Luce, R. R. Bush, \& E. Galanter (Eds.), Handbook of mathematical psychology (pp. 103-189). New York: Wiley. 
Macmillan, N. A., \& Creelman, C. D. (1991). Detection theory: A user's guide. New York: Cambridge University Press.

Mayorga, A. J., Popke, E. J., Fogle, C. M., \& Paule, M. G. (2000). Similar effects of amphetamine and methylphenidate on the performance of complex operant tasks in rats. Behavioural Brain Research, 109, 59-68.

Mehta, M. A., Owen, A. M., Sahakian, B. J., Mavaddat, N., PicKARD, J. D., \& RobBIns, T. W. (2000). Methylphenidate enhances working memory by modulating discrete frontal and parietal lobe regions in the human brain. Journal of Neuroscience, 20, RC 65: 1-6.

Money, E. A., KirK, R. C., \& MCNAughton, N. (1992). Alzheimer's dementia produces a loss of discrimination but no increase in rate of memory decay in delayed matching to sample. Neuropsychologia, 30, 133-143.

PARKes, M., \& White, K. G. (2000). Glucose attenuation of memory impairments. Behavioral Neuroscience, 114, 307-319.

Poncelet, M., Chermat, R., Soubrie, P., \& Simon, P. (1983). The progressive ratio schedule as a model for studying the psychomotor stimulant activity of drugs in the rat. Psychopharmacology, 80, 184-189.

Prendergast, M. A., Jackson, W. J., Terry, A. V., Kille, N. J., Arneric, S. P., Decker, M. W., \& Buccafusco, J. J. (1998). Agerelated differences in distractibility and response to methylphenidate in monkeys. Cerebral Cortex, 8, 164-172.

PuUmala, T., \& Sirvio, J. (1998). Changes in activities of dopamine and serotonin systems in the frontal cortex underlie poor choice accuracy and impulsivity of rats in an attention task. Neuroscience, 83, 489-499.

Ragozzino, M. E. (2000). The contribution of cholinergic and dopaminergic afferents in the rat prefrontal cortex to learning, memory, and attention. Psychobiology, 28, 238-247.

Rajkowski, J., Kubiak, P., \& Aston-Jones, G. (1992). Activity of locus coeruleus (LC) neurons in behaving monkeys varies with changes in focused attention. Society for Neuroscience Abstracts, 18, 538.

Rapport, M. D., Carlson, G. A., Kelly, K. L., \& Pataki, C. (1993). Methylphenidate and desipramine in hospitalized children: I. Separate and combined effects on cognitive function. Journal of the American Academy of Child \& Adolescent Psychiatry, 32, 333-342.

RobBins, T. W., \& EveritT, B. J. (1995). Central norepinephrineneurons and behavior. In F. E. Bloom \& D. K. Kupfer (Eds.), Psychopharmacology: The fourth generation of progress (pp. 363-372). New York: Raven.

RoberTs, W. A. (1972). Short-term memory in the pigeon: Effects of repetition and spacing. Journal of Experimental Psychology, 94, 74-83.
Russell, V. A., DE Villiers, A. S., SAgVolden, T., LAmm, M. C. L., \& TALJAARD, J. J. F. (2000). Methylphenidate affects striatal dopamine differently in an animal model for attention-deficit/hyperactivity disorder: The spontaneously hypertensive rat. Brain Research Bulletin, 53, 187-192.

SCHALl, U., KeYSERS, C., \& KAST, B. (1999). Pharmacology of sensory gating in the ascending auditory system of the pigeon (Columba livia). Psychopharmacology, 145, 273-282.

SEIDEN, L. S., ANDRESEN, J., \& MACPHAIL, R. C. (1979). Methylphenidate and $d$-amphetamine: Effects and interactions with alphamethyltyrosine and tetrabenazine on DRL performance in rats. Pharmacology, Biochemistry \& Behavior, 10, 577-584.

Solanto, M. V. (1998). Neuropsychopharmacological mechanisms of stimulant drug action in attention-deficit hyperactivity disorder: A review and integration. Behavioural Brain Research, 94, 127-152.

THOMPSON, D. M. (1974). Repeated acquisition of behavioral chains under chronic drug conditions. Journal of Pharmacology \& Experimental Therapeutics, 188, 700-713.

THOMPSON, D. M. (1976). Repeated acquisition of behavioral chains: Effects of methylphenidate and imipramine. Pharmacology, Biochemistry \& Behavior, 4, 671-677.

VolKow, N. D., WANG, G.-J., Fowler, J. S., LOGAN, J., Gerasimov, M., Maynard, L., Ding, Y.-S., Gatley, S. J., Gifford, A., \& FRANCESCHI, D. (2001). Therapeutic doses of oral methylphenidate significantly increase extracellular dopamine in the human brain. Journal of Neuroscience, 21, RC 121: 1-5.

WhITE, K. G. (1985). Characteristics of forgetting functions in delayed matching to sample. Journal of the Experimental Analysis of Behavior, 44, 15-34.

White, K. G. (2001). Forgetting functions. Animal Learning \& Behavior, 29, 193-207.

White, K. G., \& Ruske, A. C. (2002). Memory deficits in Alzheimer's disease: The encoding hypothesis and cholinergic function. Psychonomic Bulletin \& Review, 9, 426-437.

White, K. G., Ruske, A. C., \& Colombo, M. (1996). Memory procedures, performance and processes in pigeons. Cognitive Brain Research, 3, 309-317.

Winsberg, B. G., Kupietz, S. S., Sverd, J., Hungund, B. L., \& YounG, N. L. (1982). Methylphenidate oral dose plasma concentrations and behavioral response in children. Psychopharmacology, 76, 329-332.

Wolkowitz, O. M., Tinklenberg, J. R., \& Weingartner, H. (1985). A psychopharmacological perspective of cognitive functions: II. Specific pharmacologic agents. Neuropsychobiology, 14, 133-156.

\section{APPENDIX}

Table A1

Doses of Methylphenidate and Administration Routes in Previous Studies With Rats and Pigeons

\begin{tabular}{|c|c|c|c|}
\hline Study & Species & $\begin{array}{c}\text { Dose MPH } \\
(\mathrm{mg} / \mathrm{kg})\end{array}$ & Route of Injection \\
\hline Brandon et al. (2001) & rat & $2,5,10$ & intraperitoneal \\
\hline Carey et al. (1998) & rat & 3 & intraperitoneal \\
\hline Eckerman et al. (1987) & rat & $1,3,8,9$ & intraperitoneal \\
\hline Gatley et al. (1996) & rat & 10 & intraperitoneal \\
\hline Gaytan et al. (1997) & rat & $0.6,2.5,10$ & subcutaneous \\
\hline Gerasimov et al. (2000) & rat & 5,10 & intraperitoneal \\
\hline Kline, Yan, Bao, Marion, and Dixon (2000) & rat & 5 & intraperitoneal \\
\hline Mayorga et al. (2000) & rat & $1.12,2.25,4.5,9,18$ & intraperitoneal \\
\hline Poncelet et al. (1983) & rat & 4,8 & intraperitoneal \\
\hline Russell, de Villiers, Sagvolden, Lamm, and Taljaard (2000) & rat & 3 & intraperitoneal \\
\hline Schall, Keysers, and Kast (1999) & pigeon & $0.3,1$ & intramuscular \\
\hline Seiden, Andresen, and MacPhail (1979) & rat & $2.5,5,10,20$ & intraperitoneal \\
\hline Thompson (1974) & pigeon & $5,10,20$ & intramuscular \\
\hline Thompson (1976) & pigeon & $2.5,5,10,20$ & intramuscular \\
\hline
\end{tabular}

